\title{
The geometry of algebraic varieties: special issue in honour of Olivier Debarre
}

\section{Daniel Huybrechts ${ }^{1}$. Joel Kamnitzer ${ }^{2}$}

Published online: 7 March 2022

(c) The Author(s), under exclusive licence to Springer-Verlag GmbH Germany, part of Springer Nature 2022

This special volume of Mathematische Zeitschrift is dedicated to Olivier Debarre, in recognition of his service to Mathematische Zeitschrift as its managing editor for 13 years, and in admiration of his many contributions to algebraic geometry.

Publisher's Note Springer Nature remains neutral with regard to jurisdictional claims in published maps and institutional affiliations.

$凶 \quad$ Joel Kamnitzer

mathzeit@math.toronto.edu

Daniel Huybrechts

huybrech@math.uni-bonn.de

1 Mathematical Institute, University of Bonn, Endenicher Allee 60, 53115 Bonn, Germany

2 Department of Mathematics, University of Toronto, 40 St. George Street, Toronto, ON M5S 2E4, Canada 